\title{
20. \\ A systems approach to mining safety: an application of the Swiss Cheese Model
}

\author{
by J. Bonsu* ${ }^{*}$ W. van Dyk ${ }^{\dagger}$, J-P. Franzidis*, F. Petersen ${ }^{\ddagger}$, and
}

A. Isafiade*

\section{Synopsis}

Achieving zero harm in the mining industry is still a big challenge worldwide. A potential major step towards remedying the situation is a good understanding of the processes that lead to accidents in the industry. The Swiss Cheese Model has had a significant impact on the understanding of the causes of accidents in high-risk industries. In this paper, an accident analysis framework based on the Swiss Cheese Model is developed and tested against a previous mining disaster. The developed framework has the potential to enhance the understanding of the factors that contribute to accidents in the mining sector.

\section{Keywords}

Safety, accident causality, risk assessment, Swiss Cheese Model, analysis framework.

\section{Introduction}

It is well known that safety is still a big challenge in mining operations worldwide. This assertion is supported by recent mining disasters such as the Crandall Canyon disaster in the USA (6 August 2007), the Harmony Gold mine deaths in South Africa (June, 2009), the Soma mining disaster in Turkey (May, 2014), the Chile mining accident (5 August 2010), and the Xiaojiawan coal mine disaster in China (29 August 2012). Although mining employees represent only $1 \%$ of the global workforce, they account for about $8 \%$ of workplace fatalities. Workplace injuries in the mining industry worldwide have also been reported to be very high by the International Labour Organization (ILO, 2010).

The understanding of accident causality is a major step in the quest to reduce accidents. Accident modelling techniques provide the necessary platform for the interpretation and understanding of accidents at workplaces. Accident models provide a conceptualization of the characteristics of the accident process by showing the relationship between causes and effects. They explain why accidents occur, and are used as techniques for risk assessment during system development (Qureshi, 2008). During accident investigations, accident models impose patterns on the understanding of the accidents and influence both the data collected and the factors identified as causative. Since accident models influence the factors considered in any accident investigation, they may either act as a sieve and bias toward allowing for only certain events and conditions, or they may broaden the scope of the investigation by forcing consideration of factors that are often left out (Leveson, 2004). The importance of accident models in the quest for safer work environments makes the choice of the right model a crucial decision.

The Swiss Cheese Model developed by Reason (1990) is widely known for its contribution to the understanding of the factors that need to be considered during the investigation of accidents in a complex system. The model incorporates the basic components of all successful production systems such as decision-makers, line management, preconditions for effective work, production activities, and safeguards against known hazards. Effective production is achieved only when the right decisions are taken at each level of the production system. Under certain circumstances, the accident process starts when fallible decisions taken at the executive and management level are propagated through the various components of the production system. These decisions create 'holes' in the barriers put in place to prevent accidents. An accident is likely to occur when holes in the various layers of safeguards line up for the accident trajectory to be complete.

Although the Swiss Cheese Model is generally accepted as being able to depict situations leading to accidents in production systems, it has also been criticized as lacking sufficient details for practical applications

Department of Chemical Engineering, University of Cape Town, South Africa.

+ Arete Consultants (Pty) Ltd.

\& Faculty of Engineering and the Built Environment, University of Cape Town, South Africa.

(c) The Southern African Institute of Mining and Metallurgy, 2016. ISSN 2225-6253. Paper received Apr. 2015; revised paper received Feb. 2016. 


\section{A systems approach to mining safety: an application of the Swiss Cheese Model}

(Shappell and Wiegmann, 2000). A further publication by Reason, Hollnagel, and Paries (2006) admitted that the Swiss Cheese Model was not intended for such details, but is a simplification intended to make it easier to understand the essential features of an accident in an organization. In an attempt to deal with this deficiency, various analysis techniques based on the Swiss Cheese Model have been developed to meet the specific needs of various industries. Examples of such techniques available in the literature are the Human Factor Analysis and Classification System (HFACS) by Wiegmann and Shappell (1997), the Incident Cause and Analysis Model (ICAM) by de Landre et al. (2006), the Wheel of Misfortune (0'Hare, 2000), and the Behaviour Safety method (Benedyk and Minister, 1998).

In this paper an accident analysis technique applicable to the mining industry is introduced and explained. The technique is based on the ICAM model (de Landre et al., 2006), which in turn is based on the Swiss Cheese model of Reason.

\section{The accident analysis framework}

An analysis framework (Figure 1) was developed to analyse accident data from the mining industry. The need for such a framework stems from the current authors' belief that existing frameworks are overly complex and do not adequately account for all the factors that contribute to accidents in the mining industry. The aim was to develop a systemic framework that is simple but applicable to accident causality in the mining context. The framework has three broad sections, namely: causal analysis, agency and barrier analysis, and metadata. The three sections of the framework are described next.

\section{Causal section}

The first section of the framework is responsible for the analysis of accident causality. Accident causality in this framework is described in a similar manner to the Mark III version of the Swiss Cheese Model (Reason, 1997). It is divided into three levels, viz. proximal causes, workplace factors, and systemic factors, as described below.

\section{Proximal causes}

The first level of the causal section seeks to identify the activities that lead directly to an accident. These activities usually lead to the breaking of safety barriers, leading to accidents. These are subdivided into slips and lapses, mistakes, violations, and non-human causes. The choice to stay with this categorization is due to the fact that these terminologies (slips, lapses, mistakes, and violations) are already being used in the safety parlance. These subdivisions (slips, lapses, mistakes, and violations) cover all possible ways human error can lead to accidents.

Slips and lapses are used in this framework to represent all situations in which an adequate plan fails to achieve its intended purpose due to a distraction while carrying out the original plan, or in which there is a design flaw or a change in the usual situation which is not in the knowledge of the offender. This is synonymous with 'skilled based errors' in the HFACS (Wiegmann and Shappell, 1997) framework or 'action errors' in the Wheel of Misfortune framework (O'Hare, 2000).

The term mistake is used in the newly developed framework to describe all situations in which a plan carried out proves to be inadequate. Mistakes are due to wrong judgement, which may in turn be due to inadequate knowledge or a wrong interpretation of a situation. Mistake as used in this framework is comparable to 'decision error' in the HFACS framework and 'diagnosis and procedure errors' in the Wheel of Misfortune framework.

Violations are used in this framework to describe situations where there is a deliberate attempt not to follow laid-down procedure or rules. Violations are grouped into routine violations and exceptional/deviant violations. Routine violations involve all the times when rules are breached to save time, reduce effort, or for any other reason; deviant violations are out-of-the-blue violations. Routine violations are widespread and are indicative of a flaw in the work system. These are difficult to predict and control. The same terminologies are used in the HFACS framework.

Non-human causes: This category was created to accommodate situations in which human error of the person at the workplace is not directly involved in the cause of an accident. Events such as sudden failure of equipment, structures, natural disasters etc., are classified under this category.

\section{Workplace factors}

This level of the framework addresses conditions at the workplace or in the work environment that contribute or lead to human error, which in turn leads to the accident. This level

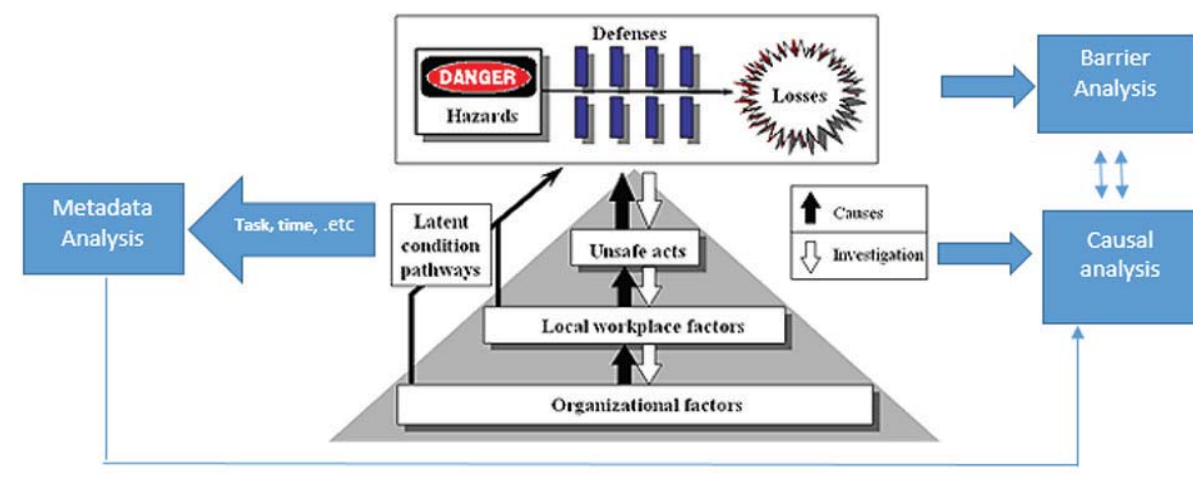

Figure 1-An analysis framework adapted from the Swiss Cheese Model 


\section{A systems approach to mining safety: an application of the Swiss Cheese Model}

is synonymous with pre-condition for unsafe act in the HFACS framework (Wiegmann and Shappell, 1997, 2001), local conditions in the Wheel of Misfortune framework, and task/environmental condition in the ICAM model (de Landre, Gibb, and Walters, 2006).

The de Landre paper clearly shows nine categories under this section, viz. working conditions, time pressures, resources, tool availability, job access, task complexity, fitness for work, workload, and task planning. Under workplace factors, the HFACS framework identifies adverse mental state, adverse physiological state, physicalmental limitation (sub-categories under condition of operators), physical environment, technological environment (subcategories under environmental factors), crew resource management, and personal readiness (sub-categories under personnel factors) as the conditions that can lead to accidents (Wiegmann and Shappell, 1997, 2001). The authors of this paper are of the opinion that the aforementioned categories are overly ramified and hence may defeat the purpose of ease of use. O'Hare (2000) also pointed out the potential conflict when incidents are to be classified under operator conditions and personnel factors.

To be able to choose factors affecting the performance of workers in the mining context, the workplace model, also known as the Nertney Wheel (Bullock, 1979), was adopted for the framework developed in this paper. The Nertney Wheel (Figure 2) identifies four components necessary for every safe and productive system, i.e. competent people, safe work practices, fit-for-purpose equipment, and a controlled work environment.

The newly developed framework identifies deficiencies in the above four components as ways in which workplace factors can lead to error- or violation-producing conditions, which lead to accidents or affect performance. The components are described below.

> Competent people-The competence of the person used for a particular task is essential for its success or otherwise. This category of the framework is intended to cater for situations in which the quality of the human resource employed leads to the committing of errors. It may be compared to substandard conditions of operator in the HFACS framework

- Fit-for-purpose equipment-is a necessity for safe production. This category is included in the framework developed in this paper to cater for situations in which the equipment used is not fit for purpose and thereby

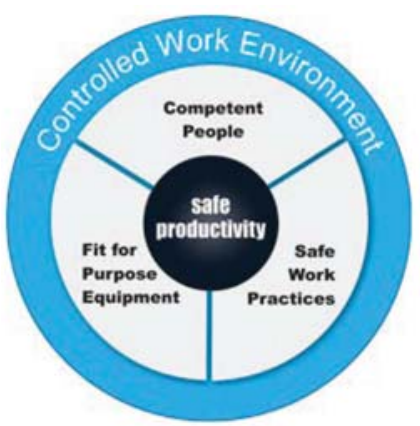

Figure 2-The Nertney Wheel (Bullock, 1979) influences the output of the task or the behaviour of the operators. It is analogous to technical environment in the HFACS framework and resources and interface in the Wheel of Misfortune framework

- Safe work practices - Formal safe work practices, such as operating procedures, are needed for safe production in any organization. This category is included in the framework to cater for situations in which there is no standard procedure on how a particular task is to be carried out or where the standard procedures proves inadequate for safe completion of the task

- Controlled work environment-This category of the framework describes situations where the quality of the working environment creates error- or violationproducing conditions. It is further divided into physical and behavioural environments:

- Physical environment includes, but is not limited to, situations such as a noisy environment, inadequate lighting, poor ventilation, and slippery floors, which could lead to error- or violationproducing conditions. This category is similar to 'physical environment' in the HFACS framework

- Behavioural environment describes situations in which unsafe behaviours are either condoned or not frowned upon. Behavioural environment as used in this study is analogous to "crew resource management' in the HFACS framework (which embodies poor leadership and poor coordination). Paul and Maiti (2008) found that safe behaviour is improved by the presence of a social support group.

\section{Systemic factors}

This layer of the framework identifies ways in which the actions of the top hierarchies of organizations contribute to an accident process. These are similar to those discussed as organizational factors in the ICAM model (de Landre, Gibb, and Walters, 2006). According to Reason, Hollnagel, and Paries (2006), there could be two failure pathways - active and latent. In the active failure pathway, the systemic factors create error- and violation-producing conditions in the workplace, which in turn creates errors and violations, leading to the breaching of defences and the accident. In the latent failure pathway, the systemic factors are directly responsible for the failure of the defences, and therefore no active human error is present. This level is synonymous with organizational factors in the HFACS framework and global conditions in the Wheel of Misfortune. While the last layer of the HFACS framework broadly categorizes such factors into organizational climate, resource management, and organizational process, the Wheel of Misfortune categorizes them into philosophy, policies, and procedures (0'Hare, 2000). In the view of the authors of this paper, none of the aforementioned classifications clearly identifies the exact ways in which the decisions of managers affect the behaviour of their subordinates. To achieve such an aim, elements of every good management safety management system were adopted in the newly developed framework. The authors conclude that deficiencies in these systems represent the various ways in which managements contribute to accidents. The components are discussed below. 


\section{A systems approach to mining safety: an application of the Swiss Cheese Model}

> Training and competence-This category of the framework addresses situations where the training offered to a worker does not help the worker to perform the required task in a safe way. It also includes situations when a worker has not been found competent before being assigned tasks

> Contractor management-This involves situations where the absence of company standards regarding work performed by employees of contractor companies results in unwanted events. This includes making sure that employees of contracting companies have received the necessary training on tasks they perform and that they adhere to the safety standards of the company

> Design-This category of the framework represents situations when poor design of equipment or the workplace leads either directly to accidents or to physical environmental problems

- Management of change-Changes that occur in organizations introduce new risks into the system. This category covers situations where management's inability to appreciate the full risk that comes with a new project, equipment, or task leads to an accident or error/violation-producing condition in the workplace

> Hazard identification-Controls put in place can only protect workers against hazards for which they were designed. This category of the framework represents situations in which there were no organizational controls for a hazard due to lack of identification. This could also be cited in situations in which the controls that were put in place could not contain the magnitude of the event when it occurred. In this case the hazard was identified, but there was a poor understanding of its magnitude and/or mechanism of release

> Monitoring and auditing-For safe production there must be systems of control in place. These control systems must be constantly audited and monitored to ensure that they are adhered to and also that they are sufficient to deal with the ever-changing working environment. This category is included in the framework to identify situations in which lack of monitoring and auditing of existing controls leads to accidents or error/violation-producing conditions in the workplace

> Maintenance management-This category of the framework covers all situations where poor maintenance of equipment and structures leads to accidents or error/violation-producing condition in the workplace. A culture of poor equipment maintenance can lead to both equipment and workplace deficiencies

- Resource provision-This category covers situations in which failure of management to provide the physical resources needed for the accomplishment of tasks leads to accidents or error- or violation-producing condition in the workplace. This usually happens during budget optimization decisions

- Strategic decision/planning - There are times in which an organization is faced with conflicting safety and production goals. This category of the framework covers situations in which the organization's choice of which goal should have prominence contributes to the accident process. For example, a decision to maximize profit by reducing the workforce

> Risk management-This category of the framework represents situations in which the refusal to deal properly with an identified risk, manage a known problem in the organization, or use effective risk management technique serves as a root cause of an accident

> Leadership-This category is included in the framework to cater for situations such as ineffective supervision, failure to correct deviant behaviour, and any other situation in which actions or inactions of leaders could have prevented an incident

- Work scheduling-This category is included in the framework as a systemic factor to cater for situations in which work schedule (continuous night shift, overtime, task coinciding with bad weather, etc.) serves as a root cause of an accident

- Emergency response-This category caters for situations in which the lack of proper emergency procedures exacerbates the effect of an accident or creates another accident.

\section{Hazard and barrier analysis}

The hazard and barrier analysis section of the framework was designed to capture information about the accidentcausing agents and the safety barriers broken in each accident. This was done with the belief that the information adds meaning to the results obtained from the causal section.

\section{Safety barriers}

This section of the framework records the safety barriers that failed during the accident process. Safety barriers can be defined as any means (physical or non-physical) instituted to prevent, control, or mitigate accidents (Hollnagel, 2008). The need for safety barriers in industry arises from the fact that the nature of some industrial activities is such that it is not always possible to remove all hazards by design. In such situations the safety of employees is ensured by placing a barrier between them and the hazard. This implies that the harm from a hazard reaches a target only when there is no safety barrier to prevent it, or the barriers put in place were not effective. The nature of the safety barriers in place also tells a lot about the nature of the industry and the kinds of unsafe acts that will be prevalent in such an industry. The ICAM framework also has a barrier analysis section.

\section{Accident-causing agencies}

This section of the framework records information on the hazards/agencies involved in each of the accidents analysed. A hazard is defined as a source of harm to people or damage to property or the environment. A major challenge in the categorization of dangerous occurrences in the mining industry is that there is no standard way of categorization. Different countries classify the same or similar incidents differently. For example the terms 'fall of ground' and 'roof fall' mean the same thing in the South African and the US mining industries. This makes it necessary for any analyst who wants to apply this framework to understand how the country involved classifies its accidents. 


\section{A systems approach to mining safety: an application of the Swiss Cheese Model}

\section{Metadata}

Metadata can simply be described as data about data or data that describes data. Metadata was chosen to elucidate other factors that may have influenced accidents. For example, knowledge of a particular time in which most human errors/violations occur could help in understanding why those errors/violations are occurring. The variables chosen under this category were time of accident, day of accident, activity the victim was involved in that resulted in the accident, place of the accident (underground, surface etc.), status of the victim (contractor or company employee), age of victim, relevant work experience, land the last vacation period. This information may not be very significant on an individual basis, but when used together proved very useful. Although the studies of Patterson and Shappell (2010) incorporated some situational data, metadata has never been formally integrated into any of the frameworks that have adopted the Reason $(1990,1997)$ model.

Now that the framework has been explained, its applicability is tested by applying it to an actual mining disaster.

\section{Application of framework to the Jim Walter Resources mine disaster}

The Jim Walter Resources mine disaster is one of the worst mining disasters in the USA in recent times. This section starts with a summarized version of the official account provided by the Mine Health and Safety Administration (2001). The causes identified by the investigation are then mapped onto the framework.

On Sunday 23 September 2001, a roof fall followed by two separate explosions occurred in an underground coal mine owned by Jim Walter Resources, leading to the fatal injury of 13 miners. The two explosions occurred at approximately 5:20 pm and 6:15 pm during a non-production afternoon shift.

Prior to the first explosion, three miners (a foreman, a longwall machine operator, and a helper) were building cribs to address deteriorating roof and rib conditions in the entry of a section near a battery charging station. The deteriorating conditions had been identified by earlier shifts and reported for repairs.

While they were building the cribs, the roofing condition continued to deteriorate as small rocks began to fall and water began pouring steadily from the roof. This was followed by several lumps, which caused the three miners undertaking the repair to take a few steps backwards. At approximately 5:17 pm, they heard sounds indicating the possibility of a broken roofbolt. The fall of a large rock and the entire roof followed subsequently.

Within minutes of the roof fall, the first explosion occurred, resulting from the ignition of the methane-air mixture by an arcing damaged battery. The explosion injured four miners (the three building the cribs and a fourth delivering building materials at the time of the explosion) and also disrupted the air flow, allowing methane to accumulate in that section of the mine. The explosion also caused visibility issues at the section of the explosion and other sections of the mine.

The foreman instructed an electrician to ensure that the electrical power to the section was turned off. Though the high-voltage electrical circuit for the section was deenergized, a track haulage block light system that extended into the section remained live. The foreman left the section to inform the control room about the explosion. He was able to inform the people in the control room about the roof fall and explosion via a telephone outside the section. He also told them about the critical condition of one of the injured miners and hence the need for an ambulance, emergency help, and a life-support helicopter.

The people in the control room mobilized other miners who were underground at the time of the first explosion to help with the situation in the affected section. While some miners were made aware of the gravity of the situation and evacuated the mine, most of the other miners who went and helped with the rescue mission were under the impression that an ignition incident had occurred. Five of these miners entered the section affected by the explosion to help rescue the injured miners.

At 6:15 pm, a second methane explosion occurred. This explosion propagated to the other sections of the mine via coal dust, resulting in at least 12 fatalities and widespread destruction of ventilation controls throughout the mine. The second explosion was most likely caused by the ignition of the methane-air mixture by the track haulage block light system. Nineteen miners were able to evacuate the mine.

Mine rescue teams were dispatched to the accident scene. One of the dispatched teams found three fatally injured miners and one severely injured miner. The injured miner died the next day after an operation. By 8 November, the bodies of 12 more victims were discovered by recovery teams.

The MHSA investigation established the following factors as contributing to the accident.

1. During the drilling of the cable bolt holes, the miners failed to fully appreciate the seriousness of the roof condition and hence did not report to their superiors. Had they reported, the roof fall may have been avoided. The miners' failure to report the situation may have been due to the fact that there had not been a previous roof fall in areas where cable bolts had been installed. Hence existing standards did not include checking for abnormal or unexpected roof conditions and drawing the attention of superiors. It was suggested that workers be made to understand the principle of roof anchorage

2. The ignition source for the second explosion was probably the block light system in the section that remained energized. Although the electrician was instructed to de-energize the power to the section following the first explosion, he failed to de-energize the track haulage block light system. He might have thought that de-energizing the high-voltage electrical circuit for the section would also de-energize the haulage block light system that extended into the section of the explosion. The foreman also tried contacting the people at the surface to de-energize all underground power sources, but was unsuccessful because the telephone was not working

3. Analysis showed that rock dust application was inadequate, which might have increased the effect of the second explosion. The mine management had no procedure of routine checks or re-applying dust in 


\section{A systems approach to mining safety: an application of the Swiss Cheese Model}

areas of need. They relied on external inspectors. There were 99 violations of the combustible materials and rock dusting standards in the year preceding the incident

4. A timely mine evacuation would have greatly reduced the impact of the accident. The investigation revealed that there was enough information to warrant the order of a mine evacuation, but that did not happen. Miners not trained for emergency rescue missions were used. This exacerbated the consequences of event. In addition, all miners were not participating in fire drills every 90 days, as required by mining regulations.

The following sections apply the various categories of the newly developed framework to the above summary of the Jim Walter Resources mine incident.

\section{Agency and barrier analysis}

The agencies identified in this accident include roof fall, methane, and coal dust explosion. The safety barriers that could have prevented the incident include an adequate risk/situational assessment and communication by the miners; roofbolts; a methane monitoring system; a properly isolated electrical system; ignition sources control; adequate rock dust application and ventilation; and good emergency planning (a mitigating barrier). While these agencies are amongst the most common accident-causing agencies, they could have been prevented or their impact reduced. Another understanding that can be obtained from the barrier analysis is that most large-scale accidents are possible only when multiple barriers fail. Reason (1998) suggests that only a poor safety culture can lead to the failure of multiple layers of barriers.

The authors of this paper are of the view that although in this situation there seemed to be enough signals to have warned the miners that the roof was unstable, the act of risk and situational assessment is not a very formidable safety barrier in preventing roof falls. This is based on the fact that there is a limitation to the degree to which visual inspections can adequately identify a roof situation. The authors suggest that a much more advanced technical solution beyond sound testing and visual inspection should be adopted. Another fact that is apparent from the barrier analysis is that most of the barriers are not self-enforcing and hence require cooperation with humans. This makes accident analysis techniques/frameworks developed from human error models very important in the quest to understand accidents in the mining context.

The above analysis has shown that a barrier and hazard analysis has the potential for identifying the preliminary causes of an accident, which can also give hints on important routes that the causal analysis of the accident should follow.

\section{Metadata analysis}

Information that qualifies as metadata in this accident includes the following.

> The incident happened during a non-productive maintenance shift

> The activity being carried out when the incident occurred was the building of cribs

> The three incidents happened between $5 \mathrm{pm}$ and $7 \mathrm{pm}$
> The workers involved in the original incident were a foreman, a longwall machine operator, and a helper

> There were several violations of standards by the mine management before the incident.

As stated earlier, this information does not say much about a single incident, but during the analysis of several incidents, patterns can be identified.

\section{Causal analysis}

Table I shows the results of mapping the causes of the accident identified by the MHSA investigation onto the new framework. A reason is provided for each framework category cited as contributing to the incident. Every causal factor identified is traced to the systemic factor that might have served as its root cause. For example, the first direct cause identified by the analysis of the accident is failure of the miners to fully understand the seriousness of the roof situation (a mistake). The workplace factors identified as leading to the mistake were that the existing procedures did not cover it (unsafe work practices) and that the requisite competence to adequately assess the situation was lacking.

Failure in the hazard identification process during procedure writing and inadequate training were the systemic factors identified as leading to these workplace factors.

From Table I it is also apparent that the complex design of the underground electrical system (fit-for-purpose equipment) was the main workplace factor identified as leading to the direct cause (slips and lapses). The fact that a single section needed to be de-energized at two different places might have contributed to the error. Failure to carry out adequate rock dusting (routine violation) at the complex electrical system and inadequate dusting (physical environment) was another human error that exacerbated the effect of the accident. There were 99 prior rock-dusting standard violations, which also confirms the fact that it was a routine error. It can also be inferred that while poor design and poor maintenance management were systemic factors leading to the deficiencies identified at the workplace, adequate emergency procedures could have mitigated the impact of the accident. This direct cause was linked to a workplace environment (behavioural environment) where violations were condoned. Another routine violation identified in this study was failure to follow proper evacuation procedures. This may have been due to the fact that there were no trained people to conduct the emergency evacuation (competent people). These findings support Reason's $(1990,1997)$ theory that an accident has both direct and indirect causes. It also confirms the assertion that human errors are symptoms of deep deficiencies in the organizational structure rather than the causes of accidents in themselves. From Reason's (1990) theory of accident pathogens, it can be said that poor hazard identification, inadequate training procedures, poor design, poor maintenance management, poor risk management, and inadequate emergency procedures were the root causes of the Jim Walter Resources accident. Saleh and Cummings (2011) also pointed to accident pathogens as the root cause of the accident.

\section{Summary and conclusion}

A newly developed accident analysis framework for incidents in the mining industry has been introduced and various 


\section{A systems approach to mining safety: an application of the Swiss Cheese Model}

\begin{tabular}{|c|c|c|c|c|c|}
\hline \multicolumn{6}{|l|}{ Table I } \\
\hline \multicolumn{6}{|c|}{ Mapping of the Jim Walter Resources accident causal factors into the causal section of the new framework } \\
\hline Direct cause & Reasoning & Workplace factor & Reasoning & Systemic factor & Reasoning \\
\hline \multirow[t]{2}{*}{ Mistake } & \multirow[t]{2}{*}{$\begin{array}{l}\text { The miners failed to fully } \\
\text { appreciate the seriousness } \\
\text { of the roof condition and } \\
\text { hence did not report to } \\
\text { their superiors }\end{array}$} & $\begin{array}{l}\text { Unsafe work } \\
\text { practices }\end{array}$ & $\begin{array}{l}\text { It was a novel situation. } \\
\text { However, the standards } \\
\text { as they existed did not } \\
\text { provide for reporting the } \\
\text { roof situation during roofbolting }\end{array}$ & hence did not cater for it & $\begin{array}{l}\text { The hazard identification process } \\
\text { during the writing of procedures } \\
\text { did not consider the possibility of } \\
\text { a roof fall during maintenance, }\end{array}$ \\
\hline & & Competent people & $\begin{array}{l}\text { It was clear that the workers } \\
\text { did not fully appreciate what } \\
\text { constitutes a stable roof }\end{array}$ & $\begin{array}{l}\text { Training and } \\
\text { competence }\end{array}$ & $\begin{array}{l}\text { It seems the existing training } \\
\text { was not enough to fully equip } \\
\text { workers with the required skills. } \\
\text { The MHSA investigation made } \\
\text { recommendations to that effect }\end{array}$ \\
\hline \multirow[t]{2}{*}{$\begin{array}{l}\text { Slips and } \\
\text { lapses }\end{array}$} & \multirow[t]{2}{*}{$\begin{array}{l}\text { The electrician instructed } \\
\text { to de-energize thought the } \\
\text { whole section has been } \\
\text { de-energized }\end{array}$} & \multirow[t]{2}{*}{$\begin{array}{l}\text { Fit-for-purpose } \\
\text { equipment }\end{array}$} & $\begin{array}{l}\text { To de-energize a single section } \\
\text { totally, two separate sources } \\
\text { had to be isolated }\end{array}$ & Design & $\begin{array}{l}\text { Poor design of the workplace } \\
\text { electrical system is the root } \\
\text { cause of the error }\end{array}$ \\
\hline & & & $\begin{array}{l}\text { A malfunctioning telephone } \\
\text { hampered communication }\end{array}$ & Maintenance & $\begin{array}{l}\text { Proper maintenance of the } \\
\text { telephone system could have } \\
\text { prevented the second explosion }\end{array}$ \\
\hline $\begin{array}{l}\text { Routine } \\
\text { violation }\end{array}$ & $\begin{array}{l}\text { Failure to apply rock } \\
\text { dusting. }\end{array}$ & $\begin{array}{l}\text { Behavioural } \\
\text { environmental }\end{array}$ & $\begin{array}{l}\text { It was clear that not meeting } \\
\text { the rock dusting requirement } \\
\text { had become a norm prior to } \\
\text { the accident. } 99 \text { previous } \\
\text { violations give testimony to that }\end{array}$ & $\begin{array}{l}\text { Monitoring and } \\
\text { auditing }\end{array}$ & $\begin{array}{l}\text { Existing controls were not } \\
\text { enforced }\end{array}$ \\
\hline \multirow[t]{2}{*}{$\begin{array}{l}\text { Routine } \\
\text { violation }\end{array}$} & \multirow[t]{2}{*}{$\begin{array}{l}\text { Failure to follow proper } \\
\text { evacuation procedure }\end{array}$} & $\begin{array}{l}\text { Competent } \\
\text { people }\end{array}$ & $\begin{array}{l}\text { Miners were not trained for } \\
\text { emergency evacuation }\end{array}$ & $\begin{array}{l}\text { Training and } \\
\text { competence }\end{array}$ & $\begin{array}{l}\text { Miners were not properly trained } \\
\text { or emergency situations }\end{array}$ \\
\hline & & $\begin{array}{l}\text { Behavioural } \\
\text { environment }\end{array}$ & $\begin{array}{l}\text { Participation in fire drills } \\
\text { was not compulsory }\end{array}$ & $\begin{array}{l}\text { Monitoring and } \\
\text { auditing }\end{array}$ & $\begin{array}{l}\text { Existing controls were not } \\
\text { enforced }\end{array}$ \\
\hline
\end{tabular}

sections compared to those in existing frameworks. The use of this framework has been demonstrated by mapping identified causes of a previous mining disaster onto it. The results showed that the accident had both direct and indirect causes. Systemic factors seem to be the root cause of the direct causes. This agrees with Reason's $(1990,2000)$ analogy of accidents in high-risk industries being the result as accident pathogens. It is recommended that this framework be applied to a wider range of accident reports.

\section{Limitations}

The limitations of this study are those of most post-hoc analyses. The accuracy of the analysis depends solely on the accuracy of the accident investigation and report.

\section{Acknowledgement}

This work is based on research supported by the South African Research Chairs Initiative of the Department of Science and Technology and National Research Foundation of South Africa, which is gratefully acknowledged.

Any opinion, finding, and conclusion or recommendations expressed in this material is that of the authors and the NRF does not accept any liability in this regard.

\section{References}

BENEDyK, R. and Minister, S. 1998. Applying the BeSafe method to product safety evaluation. Applied Ergonomics, vol. 29, no 1. pp. 5-13.

BuLlock, M.G. 1979. Work process control guide. System Safety Development Centre EG and G Idaho Inc., Idaho Falls, Idaho.
De LANDRe, J., GibB, G., and Walters, N. 2006. Using incident investigation tools proactively for incident prevention. http://asasi.org/papers/2006/ Payne_Stewart_Learjet_Investigation_De\%20Landre_Gibb_Walters_Doc. pdf [Accessed 1 Feb. 2012].

Hollnagel, E. 2008. Risk + barriers = safety? Safety Science, vol. 46, no. 2. pp. 221-229.

ILO (International Labour Organization). 2010. Mining: a hazardous work. http://www.ilo.org/safework/areasofwork/hazardouswork/WCMS_124598/lang--en/index.htm [Accessed 12 Jan. 2013].

LeVESON, N.G. 2004. A new accident model for engineering safer systems. Safety Science, vol. 42. pp. 237-270.

Mine Safety and Health Administration. 2001. Report of investigation, fatal underground coal mine explosions. 23 September 2001. http://www.msha.gov/fatals/2001/jwr5/ftl01c2032light.pdf [Accessed 1 Sep. 2013].

O'HARE, D. 2000. The 'Wheel of Misfortune': a taxonomic approach to human factors in accident investigation and analysis in aviation and other complex systems. Ergonomics, vol. 43, no. 12. pp. 2001-2019.

Patterson, J.M. and Shappell, S.A. 2010. Operator error and system deficiencies: analysis of 508 mining incidents and accidents from Queensland, Australia using HFACS. Accident Analysis and Prevention, vol. 42, no. 4. pp. 1379-1385.

PAUL, P.S. And MaITI, J . 2008: The synergic role of sociotechnical and personal characteristics on work injuries in mines. Ergonomics, vol. 51, no. 5. pp. 737-767. 


\section{A systems approach to mining safety: an application of the Swiss Cheese Model}

QURESHI, Z.H. 2008. A review of accident modeling approaches for complex critical sociotechnical systems. Report no. DSTO-TR-2094. Defence Science and Technology Organization, Australia.

REASON, J. 1990. Human Error. Cambridge University Press.

ReAson, J. 1997. Managing the Risks of Organizational Accidents. Ashgate Publishng (Taylor \& Francis).

REASON, J. 1998. Achieving a safe culture: theory and practice. Work and StresS, vol. 12, no. 3. pp. 293-306.

REASON, J. 2000. Safety paradoxes and safety culture. International Journal of Injury Control and Safety Promotion, vol. 7, no. 1. pp. 3-14.

Reason, J., Hollnagel, E., and Paries, J. 2006. Revisiting the "Swiss Cheese" Model of accidents. EUROCONTROL Experimental Centre, Bretiny-surOrge Cedex, France.
Saleh, J.H. and Cummings, A.M. 2011. Safety in the mining industry and the unfinished legacy of mining accidents: safety levers and defense-in-depth for addressing mining hazards. Safety Science, vol. 49, no. 6 . pp. 764-777.

Shappell, S.A. and Wiegmann, D.A. 2000. The Human Factors Analysis and Classification System (HFACS). Report no. DOT/FAA/AM-00/7, Office of Aerospace Medicine, Washington DC. http://hfacs.com/sites/default/files/ Shappell\%20and\%20Wiegmann,\%202000.pdf [Accessed 6 April 2013].

WiEgmann, D.A. and SHAPPELL, S.A. 1997. A human error approach to accident investigation: the taxonomy of unsafe operations. International Journal of Aviation Psychology, vol. 7, no. 4. pp. 269-291.

Wiegmann, D.A. and SHAPPELL, S.A. 2001. Human error analysis of commercial aviation accidents: application of the Human Factors Analysis and Classification System (HFACS). Aviation, Space, and Environmental Medicine, vol. 72, no. 11. pp. 1006-1016. 